\title{
Phenotyping and Molecular Characterization of Extended-Spectrum Beta-Lactamases among Clinical Isolates of Gram-Negative Bacilli in Arar Tertiary Care Hospital, Saudi Arabia
}

\author{
Mohamed Soliman', Jayakumar Subramaniam², Jamith Basha Abdul Wahid ${ }^{3}$, \\ Khalid Mohammed Refaat ${ }^{4}$
}

\begin{abstract}
${ }^{1}$ Professor, Department of Microbiology and Parasitology, Northern Border University, Arar, Saudi Arabia. ${ }^{2}$ Associate Professor, ${ }^{3}$ Lecturer, Department of Microbiology, Northern Border University, Arar, Saudi Arabia. ${ }^{4}$ Specialist, Microbiology Diagnostic Lab, Arar Central Hospital, Northern Border University, Saudi Arabia. DOI: https://doi.org/10.24321/0019.5138.201805
\end{abstract}

Abstract
Objectives: The emergence of extended-spectrum $\beta$-lactamases (ESBLs) in drug-resistant Gram-negative
bacilli isolates in critically ill patients is posing a serious threat. Lack of data on the prevalence of drug-
resistant Gram-negative bacilli with respect to enzymes responsible for drug resistance in the tertiary care
hospital at Arar necessitated this study.
Methods: All the Gram-negative bacilli isolated from clinical specimens were subjected to antibiotic
susceptibility testing. Drug-resistant organisms were screened for the presence of ESBLs, and confirmed
by phenotypic methods. Molecular characterizations of these organisms were performed by conventional
PCR to identify the ESBLs genes.
Results: A total of 3711 specimens were processed over a period of one year and 428 Gram-negative bacilli
(GNB) were isolated. Out of 428 GNB, 91 (21.2\%) were ESBL producers which include Escherichia coli (46),
Klebsiella pneumoniae (33), Proteus mirabilis (11), and Klebsiella oxytoca(1). The minimum inhibitory
concentration (MIC) for ceftazidime and ceftazidime plus clavulanic acid for all the ESBL (91) isolates were
$>16 \mu \mathrm{g} / \mathrm{mL}$ and $<0.25 \mu \mathrm{g} / \mathrm{mL}$ whereas for cefotaxime and cefotaxime plus clavulanic acid the MIC was
$>32 \mu \mathrm{g} / \mathrm{mL}$ and $<0.25$ to $0.5 \mu \mathrm{g} / \mathrm{mL}$ respectively. CTX gene $44(48.3 \%)$, was predominant among all ESBL
producers; next to it was SHV $15(16.5 \%)$ and TEM $2(2.2 \%)$, and $30(32.9 \%)$ isolates had all the three genes
(CTX, SHV, and TEM).
Conclusion: The findings in our study revealed the higher prevalence of ESBL in the community. Surveillance
of antibiotic resistance with respect to ESBLs will provide a platform for framing antibiotic policy.
Keywords: Lactamases enzyme, Gram-negative bacilli, Clinical samples, Molecular epidemiology of
ESBL, Sensitivity test, Arar

Corresponding Author: Dr. Jayakumar Subramaniam, Department of Microbiology and Parasitology, Northern Border University, Arar, Saudi Arabia.

E-mail Id: drjk_micro@rediffmail.com

Orcid Id: https://orcid.org/0000-0002-1120-3407

How to cite this article: Soliman M, Subramaniam J, Wahid JBA et al. Phenotyping and Molecular Characterization of ExtendedSpectrum Beta-Lactamases among Clinical Isolates of Gram-Negative Bacilli in Arar Tertiary Care Hospital, Saudi Arabia. J Commun Dis 2018; 50(1): 22-27. 


\section{Introduction}

Gram-negative bacterial species are the most common organism isolated from clinical specimens in hospitalized patients. In recent years, infections with drug-resistant Gram-negative bacilli have been increasing. ${ }^{1,2}$ Infections with these resistant organisms remain a problem in patient management because of a limited number of antibiotics to treat them. The resistance in these organisms is due to the production of $\beta$-lactamases enzymes such as extendedspectrum $\beta$-lactamases (ESBLs), AmpC $\beta$-lactamases (AmpCs), Carbapenemase-producing Enterobacteriaceae and Metallo $\beta$-lactamases (MBLs). Studies show that the genes which produce these enzymes are located on a plasmid, which might readily jump among organisms resulting in outbreaks. ${ }^{3,4}$

Classification of $\beta$-lactamases has been based on functional characteristics of enzymes or their primary structure, but for clinician and microbiologist, functional groupings of enzymes are appropriate. ${ }^{5}$ In the functional classification, based on the ability to hydrolyze specific $\beta$-lactam classes and on inactivation properties of the $\beta$-lactamase inhibitors, there are three groups: group1 cephalosporinases, group2 serine $\beta$-lactamases, and group3 MBLs.

Group1 enzymes belong to molecular class C, hydrolysis cephalosporins, and cephamycins but have a high affinity for aztreonam. ${ }^{6,7}$ Group1 enzymes are less common when compared to Group2be ESBL enzymes. Increasing number of group2 enzymes were identified during the past 25 years due to increased identification of ESBLs. These enzymes hydrolyze various penicillin groups of antibiotics, including oxyimino- $\beta$-lactams and carbapenems. TEM1 , TEM-2, and SHE-1 enzymes belong to subgroup $2 b$ $\beta$-lactamases that readily hydrolyze penicillins and early cephalosporins. These enzymes are strongly inhibited by clavulanic acid and tazobactam. ${ }^{4}$ Subgroup2be ESBLs arises from a gene mutation in TEM-1, TEM-2, and SHV-1 enzymes. The characteristic feature of 2 be enzymes is they readily hydrolyze oxyimino- $\beta$-lactams such as cefotaxime, ceftazidime, ceftriaxone, cefepime, and aztreonam. ${ }^{8}$

Moreover, these organisms are sensitive to inhibition by clavulanic acid (CA) or tazobactam (TZB), which is a feature used in their detection by clinical laboratories.

Group2ber enzymes show increased hydrolysis of oxyimino$\beta$-lactams and show combined resistance to clavulanic acid, sulbactam, and tazobactam. ${ }^{9}$ Increased hydrolysis of carbapenems was also noticed by group $2 \mathrm{f}$ and $2 \mathrm{df}$ enzymes but they exhibit variable sensitivity to inhibition by clavulanic acid (CA) or tazobactam (TZB). ${ }^{10}$

The present study deals with isolation and characterization of Gram-negative bacilli and to investigate the prevalence of drug-resistant Gram-negative bacilli with reference to ESBLs and encoding genes. Knowledge on these drug-resistant Gram-negative bacilli and the enzymes responsible for it will help us to frame antibiotic policy in Arar hospitals.

\section{Materials and Methods}

All the samples received for bacterial culture by the microbiology laboratory of Arar Central Hospital, Saudi Arabia, during the period between August 2016 and July 2017 were included in the study. This study was reviewed and approved by the Institutional Review Board (IRB) and the Committee for Biological and Medical Ethics at Northern Border University (NBU). Informed consent was also obtained from the patients. Samples were processed using standard bacteriological techniques to identify the organisms. ${ }^{11}$ In vitro, antibiotic-susceptibility tests were done for all the aerobic Gram-negative bacilli and coccobacilli isolated using Kirby-Bauer disk diffusion method as described by CLSI (Clinical and Laboratory Standards Institute) guidelines. ${ }^{12}$ The drugs used were penicillin 10 units, ceftazidime $30 \mathrm{mg}$, cefotaxime $30 \mu \mathrm{g}$, ceftriaxone 30 $\mu \mathrm{g}$, cefepime $30 \mu \mathrm{g}$, ceftazidime $30 \mu \mathrm{g}$ and ceftazidime/ clavulanic acid (30/10 $\mu \mathrm{g})$, cefotaxime/clavulanic acid $(30 / 10 \mu \mathrm{g})$, cefoxitin (differentiate disk) piperacillin 100 $\mu \mathrm{g}$, cefpodoxime $10 \mu \mathrm{g}$, piperacillin/tazobactam 100/10 $\mu \mathrm{g}$, amikacin $30 \mu \mathrm{g}$, gentamicin $10 \mu \mathrm{g}$, ciprofloxacin $5 \mu \mathrm{g}$, imipenem $10 \mu \mathrm{g}$, and meropenem $10 \mu \mathrm{g}$. All antibiotic disks were purchased from Oxoid and Bio-Rad Company. Drug-resistant organisms were subjected to further testing for the presence of ESBLs. Escherichia coli ATCC 25922 and Pseudomonas aeruginosa ATCC 27853 were used for quality control.

\section{Detection of ESBL}

All the non-duplicate isolates of Gram-negative bacteria, which were resistant to ceftazidime and cefotaxime or having screening cut-offs $\leq 22 \mathrm{~mm}$ and $\leq 27 \mathrm{~mm}$ respectively were tested for ESBLs production by CLSI phenotypic confirmatory test (double-disk diffusion method). ${ }^{12}$

The inoculum was prepared as per the standard brothdilution recommendations. The suspension of each isolate was spread on Mueller-Hinton agar and the antibiotic disks such as ceftazidime (CAZ $30 \mu \mathrm{g})$, ceftazidime plus clavulanic acid (CAZ/CA 30/10 $\mu \mathrm{g}$ ), cefotaxime (CTX 30 $\mu \mathrm{g})$ and cefotaxime plus clavulanic acid (CTX/CA 30/10 $\mu \mathrm{g}$ ) were placed aseptically at about $10 \mathrm{~mm}$ edge-to-edge. The plates were incubated at $35 \pm 2^{\circ} \mathrm{C}$ in ambient air for $16-18$ hours and the tests were interpreted according to CLSI guidelines. ${ }^{12}$ The increase in the zone of inhibition ( $\geq 5 \mathrm{~mm}$ ) for the CAZ/CLA and CTX/CLA containing disk versus the zone diameter of the agent tested alone was considered positive for ESBL. Standard reference strain, E. coli ATCC 25922 and K. pneumoniae ATCC 700603 were used for quality control when performing the ESBL confirmatory tests. 


\section{Determination of Minimum Inhibitory Concentration}

Minimum inhibitory concentration (MIC) for ceftazidime, ceftazidime plus clavulanic acid, cefotaxime and cefotaxime plus clavulanic acid were determined by Siemens Microscan WalkAway $40 \mathrm{SI}$.

\section{Molecular Identification of ESBL Gene}

All isolates, which were positive for ESBL by phenotypic test, were subjected for a molecular study to detect the presence of gene encoding these enzymes. ESBL (CTX, TEM, SHV, GES, and PER) genes were amplified by conventional polymerase chain reaction (PCR) using a panel of primers. PureFast ${ }^{\circledR}$ Bacterial DNA mini spin purification kit, HELINI 2X ReDdye PCR Master Mix, Agarose gel electrophoresis consumables and primers (CTX, TEM, SHV, GES, and PER) are from Helini Biomolecules, Chennai, India.

\section{Bacterial DNA Purification}

One milliliter of overnight culture centrifuged at 6000 rpm for $5 \mathrm{~min}$, the supernatant discarded and the pellet was suspended in $0.2 \mathrm{~mL}$ PBS. To this $180 \mu \mathrm{L}$ of lysozyme digestion buffer and $20 \mu \mathrm{L}$ of lysozyme $(10 \mathrm{mg} / \mathrm{mL})$ was added and incubated at $37^{\circ} \mathrm{C}$ for $15 \mathrm{~min}$. After incubation, $400 \mu \mathrm{L}$ of binding buffer, $5 \mu \mathrm{L}$ of internal control template and $20 \mu \mathrm{L}$ of proteinase $\mathrm{K}$ was added and vortexed. It was further incubated at $56 \circ \mathrm{C}$ for $15 \mathrm{~min}$ and $300 \mu \mathrm{L}$ of ethanol was added. The entire sample was transferred into the PureFast ${ }^{\circledR}$ spin column and centrifuged for $1 \mathrm{~min}$. In order to remove the residual ethanol, the PureFast ${ }^{\circledR}$ spin column was added with $500 \mu \mathrm{L}$ wash buffer-1, centrifuged for 30-60 sec and discarded the flow-through. This step was repeated with wash buffer- 2 also and the PureFast ${ }^{\circledR}$ spin column was transferred to a fresh $1.5 \mathrm{~mL}$ micro-centrifuge tube. Finally, $100 \mu \mathrm{L}$ of elution buffer was added to the center of PureFast ${ }^{\circledR}$ spin column membrane, incubated for $1 \mathrm{~min}$ at room temperature and centrifuged for $2 \mathrm{~min}$. Purified DNA was obtained after discarding the column.

Quality and quantity of extracted DNA were checked by loading in $1 \%$ agarose gel and $5 \mu \mathrm{L}$ of extracted DNA was used for PCR amplification.

\section{PCR Procedure}

Five microliter ( $5 \mu \mathrm{L}$ ) of purified bacterial DNA, $10 \mu \mathrm{L}$ HELINI RedDye PCR Master mix and $5 \mu \mathrm{L}$ of HELINI ready-to-use primer mix was taken in the individual amplification tubes and placed into the PCR machine. PCR was performed according to the following protocol: initial denaturation at 95 으 for 5 min followed by 35 cycles each consisting of denaturation at $95 \circ \mathrm{C}$ for $30 \mathrm{sec}$, annealing at 58으 $\mathrm{C}$ for 30 $\mathrm{sec}$, extension at $72^{\circ} \mathrm{C}$ for $30 \mathrm{sec}$ and a final extension at $72{ }^{\circ} \mathrm{C}$ for $5 \mathrm{~min}$.

The amplified products were analyzed by gel electrophoresis on $2 \%$ agarose gel ( $2 \mathrm{gm}$ of agarose in $100 \mathrm{~mL}$ of $1 \mathrm{X}$ TAE buffer). PCR products were loaded after mixing with gelloading dye along with $10 \mu \mathrm{L}$ HELINI 100 bp DNA Ladder. Electrophoresis was performed at $50 \mathrm{~V}$ till the dye reached three-fourth distances and the bands were observed in UV transilluminator.

\section{Results}

A total of 3711 specimens were processed in the microbiology laboratory, which includes both inpatients and outpatients. The specimens were urine (1775), pus (856), blood (759), sputum (209), bronchoalveolar lavage (107), pleural fluid (3), synovial fluid and CSF each one. Out of 3711 specimens cultured, 428 aerobic Gram-negative bacilli were isolated from various specimens. Distribution of Gram-negative bacilli in various specimens is shown in Table 1.

Table 1.Distribution of Gram-Negative Bacilli in Various Specimens

\begin{tabular}{|c|c|c|c|c|c|c|}
\hline Organisms & Urine & Blood & BAL* & Wound Swab/ Pus swab & Sputum & Total \\
\hline Escherichia coli & 91 & 9 & 0 & 26 & 4 & 130 \\
\hline Klebsiella pneumoniae & 28 & 10 & 11 & 22 & 6 & 77 \\
\hline Klebsiella oxytoca & 0 & 0 & 1 & 2 & 0 & 3 \\
\hline Pseudomonas aeruginiosa & 4 & 2 & 6 & 20 & 7 & 39 \\
\hline Acinetobacter baumannii & 8 & 11 & 30 & 28 & 9 & 86 \\
\hline Proteus mirabilis & 24 & 4 & 6 & 22 & 6 & 62 \\
\hline Achromobacter species & 0 & 0 & 1 & 0 & 0 & 1 \\
\hline Providencia stuartii & 4 & 2 & 6 & 4 & 0 & 16 \\
\hline Enterobacter species & 0 & 1 & 0 & 3 & 0 & 4 \\
\hline Stenotrophomonasmaltophilia & 0 & 2 & 0 & 0 & 0 & 2 \\
\hline Serratia marcescens & 0 & 0 & 0 & 3 & 0 & 3 \\
\hline Alcaligenes species & 0 & 1 & 0 & 0 & 0 & 1 \\
\hline Citrobacter species & 0 & 0 & 0 & 4 & 0 & 4 \\
\hline Total & 159 & 42 & 61 & 134 & 32 & 428 \\
\hline
\end{tabular}

*BAL: Bronchoalveolar lavage 
Among 428 Gram-negative bacilli, 91(21.2\%) ESBL-producing organisms were as follows: $E$. coli (46/130), K. pneumoniae (33/77), P. mirabilis (11/62), and $K$. oxytoca $(1 / 3)$.

The minimum inhibitory concentration (MIC) for ceftazidime and ceftazidime plus clavulanic acid for all the phenotypically confirmed ESBL (91) isolates were $>16 \mu \mathrm{g} / \mathrm{mL}$ and $<0.25 \mu \mathrm{g} /$ $\mathrm{mL}$, whereas for cefotaxime and cefotaxime plus clavulanic acid the MIC was $>32 \mu \mathrm{g} / \mathrm{mL}$ and $<0.25$ to $0.5 \mu \mathrm{g} / \mathrm{mL}$ respectively.

The molecular characterization of ESBL-producing organisms was carried out using conventional PCR method. CTX gene was the predominant gene among ESBL-producing organisms $44(48.3 \%)$, followed by $15(16.5 \%)$ SHV genes and $2(2.2 \%)$ TEM. Thirty isolates (32.9\%) had all the three genes (CTX, SHV, and TEM).

The distribution of ESBL-producing organism and the genes produced by them is shown in Table 2. Figure 1 shows the amplified product of $E$. coli showing all the three genes (CTX, SHV, and TEM) and Fig. 2 shows the presence of CTX gene in various isolates.

Table 2.Distribution of ESBL-Producing Gram-Negative Bacilli and Gene Expression

\begin{tabular}{|c|c|c|c|c|c|}
\hline \multirow{2}{*}{ ESBL Gene type } & \multicolumn{5}{|c|}{ Gram-Negative Bacilli } \\
\cline { 2 - 6 } & E. coli & K. pneumoniae & P. mirabilis & K. oxytoca & Total \\
\hline CTX & 28 & 13 & 3 & - & - \\
\hline SHV & 3 & 12 & - & - & 15 \\
\hline TEM & 2 & - & - & 1 & 2 \\
\hline CTX+SHV+TEM & 13 & 8 & 11 & 1 & 91 \\
\hline Total & 46 & 33 & & & 9 \\
\hline
\end{tabular}

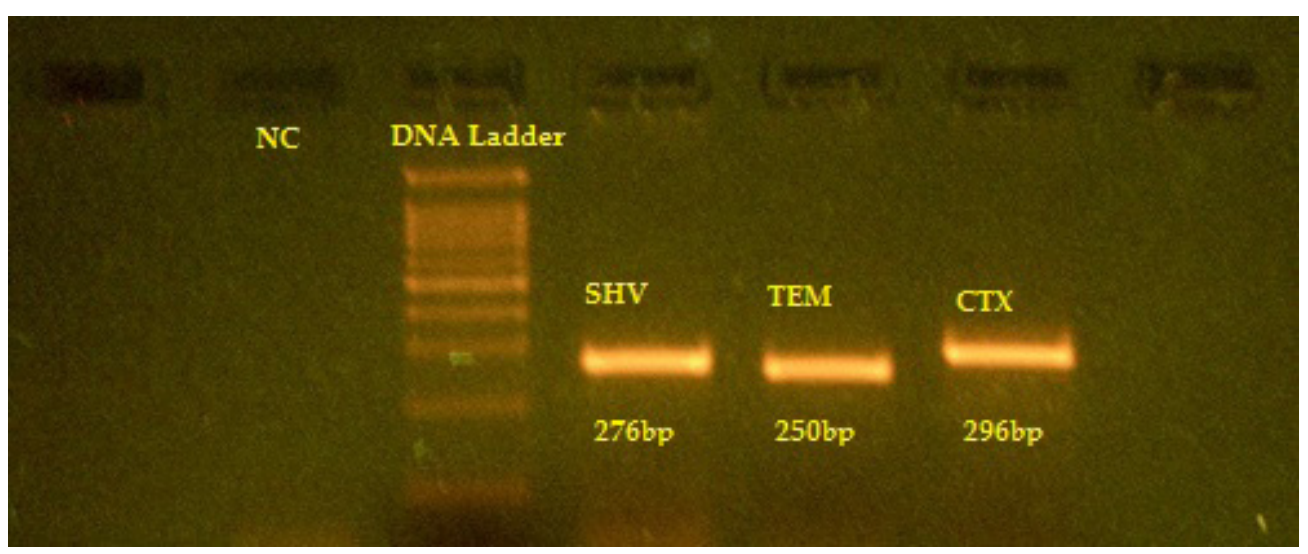

$\mathrm{NC}-$ Negative control

Figure 1.Image of PCR Amplified Product Showing all Three Genes in E. coli

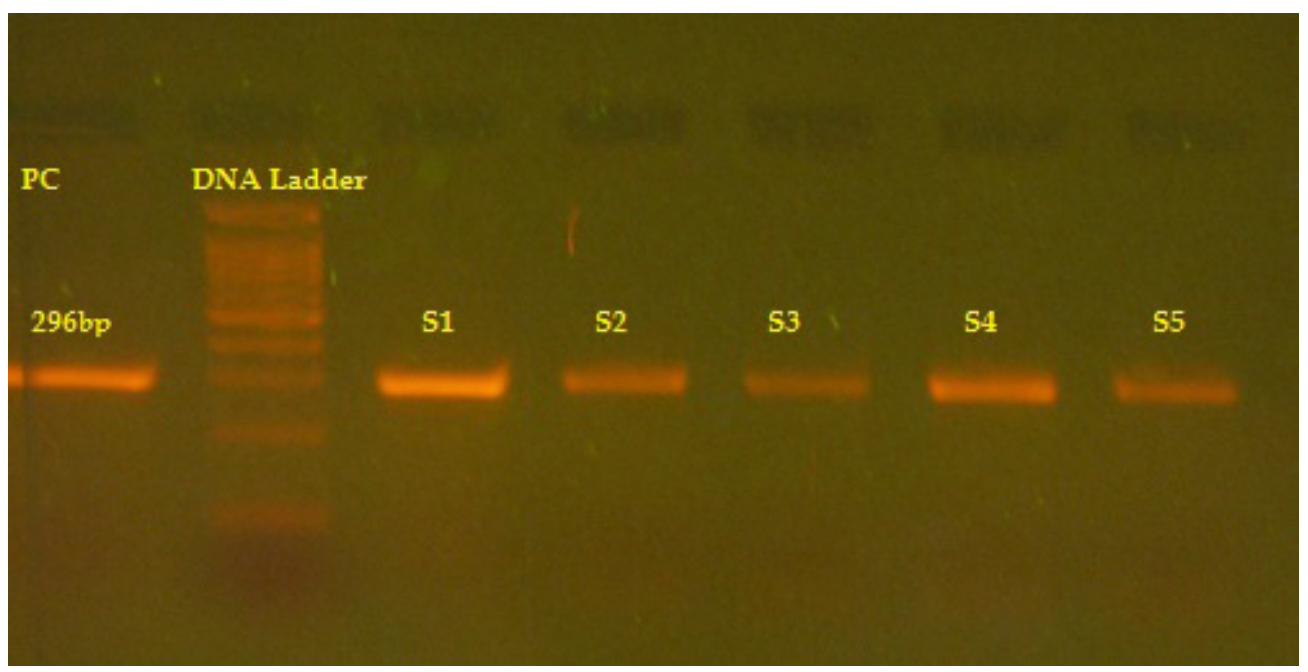

PC - Positive control, Sample 1 (S1) - E.coli, S2 - K. pneumoniae, S3 - P. mirabilis, S4 - E. coli, S5 - P. mirabilis

Figure 2.Image of PCR Amplified Product Showing CTX Gene in Various Isolates 


\section{Discussion}

Infections due to Gram-negative bacteria, particularly multidrug-resistant bacteria, remain a major problem in hospitals and nursing homes. ${ }^{13}$ These bacteria develop resistance to a large group of antibiotics by possessing various resistant genes. Recently, World Health Organization (WHO) listed pathogens into three categories such as critical, high, and medium-priority pathogens according to the urgency of the need for new antibiotics. ${ }^{14}$ Members of the family Enterobacteriaceae (including, E. coli, Klebsiella spp., Proteus spp., Enterobacter spp., Serratia spp., Proteus spp., Providencia spp., and Morganella spp.), Acinetobacter spp., and Pseudomonas spp., are in the critical-priority pathogen list as they become resistant to most of the third-generation cephalosporins.

Members of the family Enterobacteriaceae, which were resistant to most of the third-generation cephalosporins, are due to the production of extended-spectrum $\beta$-lactamases (ESBLs). These enzymes were expressed due to the presence of genes such as CTX, TEM, SHV, GES, PER and other ESBL types. ${ }^{5}$ The emergence of plasmid-mediated ESBLs among Enterobacteriaceae is high and that accounts for these organisms to be in critical priority pathogen. ${ }^{3,4}$ The present study is the first report in Arar region, Northern ProvinceSaudi Arabia, focusing on ESBL-producing Gram-negative bacilli and genes expressing these enzymes.

In our study, the prevalence of ESBLs among Gram-negative bacilli are $21.2 \%$, whereas studies from other parts of Saudi Arabia had varying rates of ESBL-producing organisms ranging from $(4.8 \%$ to $38.5 \%)$ by the members of the family Enterobacteriaceae and among non-fermenting Gram-negative bacilli, which indicates there is a constant rise in the prevalence of ESBL in Saudi Arabia. ${ }^{13,15-20}$ In comparison with the regional data, the prevalence of ESBL in our study is less.

Among family Enterobacteriaceae, K. pneumoniae (42.8\%) was the major organism to produce ESBL, followed by $E$. coli (35\%), K. oxytoca (33.3\%) and P. mirabilis (17.7\%). But in another study, ${ }^{16}$ the proportion of $E$. coli was found to be the predominant ESBL producer (46\%), and $K$. pneumoniae $(21.6 \%)$ being the next. The predominance of ESBL-producing E. coli or K. pneumoniae isolates has been varied in geographical regions. ${ }^{17,21}$ Even though there were multi-drug resistant non-fermenting Gram-negative bacilli in our study, none of them were ESBL producers. The resistance in these organisms could be due to a different mechanism of resistance such as AmpC enzyme production and efflux mechanism.

Though there are studies about the prevalence of ESBLproducing organisms in Saudi Arabia, the molecular analyses of the genes that are responsible for these enzymes are few in number, mostly concentrated in Riyadh and in the Eastern Province. ${ }^{21}$ The prevalence and molecular characterization of ESBL-producing strains were not documented in Arar region, Northern Province, Saudi Arabia. CTX gene 44(48.3\%), was the predominant gene among all ESBL producers followed by SHV 15(16.5\%) and TEM 2(2.2\%); and 30(32.9\%) isolates had all the three genes (CTX, SHV, and TEM). Even though the percentage of gene type detected in isolates varied in a different study, the predominant gene type is CTX in Saudi Arabia, which is in accordance with our observation..$^{21,22}$

CTX gene is the most common gene detected among $E$. coli (60.9\%) and TEM being the least frequently expressed ESBL gene in our study. In the study done by a university hospital in the eastern province, the observation was the same with respect to CTX but the least frequently observed gene was SHV. ${ }^{22}$ The SHV gene detection rate in $K$. pneumoniae was $36.4 \%$ but only at $6.5 \%$ of $E$. coli carried SHV; similar results were observed by another investigator in Saudi Arabia. ${ }^{23}$

The percentage of isolates expressing all three genes were: $K$. oxytoca (100\%), P. mirabilis $(8 / 11,72.7 \%), K$. pneumoniae (8/33, 24.2\%) and E. coli (13/46, 28.2\%). On the contrary, the study by Hassan et al. ${ }^{22}$ documented a different observation in which $K$. pneumoniae (68\%) was the predominant organism expressing all three genes followed by K. oxytoca (50\%) and E.coli (10\%); and none of the $P$. mirabilis harboring all three genes. The existence of all three genes in an isolate indicates that these genes are located in plasmids, which might readily jump among organisms giving rise to a chance of outbreaks in hospitals. ${ }^{3,4}$

\section{Conclusion}

The findings in this study document the prevalence of ESBL strains among family Enterobacteriaceae mainly in E. coli and Klebsiella species. The molecular study of ESBL-producing strains in Arar region, Saudi Arabia, clearly indicates that the presence of the CTX-like gene is predominant. Detection of ESBL production by Gramnegative bacteria will help us to have an interpretation and assessment of success and failure of treatment. Moreover, periodic surveillance of antibiotic resistance detects new or increasing trends of drug resistance in the organism and to assess the appropriate antibiotic in an empirical therapy.

\section{Acknowledgment}

We acknowledge the deanship of scientific research at Northern Border University for funding this project, research project number: MED-2016-1-6-F-5768.

\section{Conflict of Interest: None}

\section{References}

1. Vasoo S, Barreto JN, Tosh PK. Emerging issues in 
Gram-negative bacterial resistance: An update for the practicing clinician. Mayo Clin Proc 2015; 90(3): 395-403.

2. Pfaller MA, Segreti J. Overview of the epidemiological profile and laboratory detection of extended-spectrum beta-lactamases. Clin Infect Dis 2006; 42(Suppl. 4): S153-S163.

3. Ruppe $E$, Bidet $P$, Verdet $C$ et al. First detection of the ambler class C 1 AmpC $\beta$-Lactamase in Citrobacter freundii by a new, simple double-disk synergy test. J Clin Microbiol. 2006; 44(11): 4204-07.

4. Pitart C, Sole M, Roca I et al. First outbreak of a plasmid-mediated carbapenem-hydrolyzing OXA48 B-Lactamase in Klebsiella pneumoniae in Spain. Antimicrob Agents Chemother. 2011; 55(9): 4398-4401.

5. Bush K, Jacoby GA. Updated functional classification of $\beta$-Lactamases. Antimicrob. Agents Chemother. 2010; 54(3): 969-76.

6. Bush K. $\beta$-Lactamase inhibitors from laboratory to clinic. Clin Microbiol Rev. 1988; 1: 109-23.

7. Bush K, Freudenberger JS, Sykes RB. Interaction of azthreonam and related monobactams with $\beta$-lactamases from Gram-negative bacteria. Antimicrob Agents Chemother. 1982; 22: 414-20.

8. Queenan, Foleno AMB, Gownley.C et al. Effects of inoculum and $\beta$-lactamase activity in AmpC- and extended-spectrum $\beta$-lactamase (ESBL)-producing Escherichia coli and Klebsiella pneumoniae clinical isolates tested by using NCCLS ESBL methodology. J Clin Microbiol. 2004;.42:.269-75.

9. Robin F, Delmas J, Chanal C et al. TEM-109 (CMT-5), a natural complex mutant of TEM-1 beta-lactamase combining the amino acid substitutions of TEM- 6 and TEM-33 (IRT-5). Antimicrob Agents Chemother. 2005; 49(11): 4443-47.

10. Walther-Rasmussen J, Høiby N. OXA-type carbapenemases. J Antimicrob Chemother. 2006; 57(3): 373-83.

11. Forbes BA, Sahm DF, Weissfeld AS. Bailey \& Scott's Diagnostic Microbiology. 12th edition. CV Mosby 2007.

12. Clinical and Laboratory Standards Institute (CLSI). Performance standards for antimicrobial disk susceptibility tests; $23^{\text {rd }}$ ed. M100-S23. Wayne, PA: CLSI 2013.

13. Zowawi HM, Balkhy HH, Walsh TR et al. $\beta$-Lactamase production in key Gram-negative pathogen isolates from the Arabian Peninsula. Clin Microbiol Rev 2013;
26(3): 361-80.

14. Tacconelli E, Magrini N. Global priority list of antibioticresistant bacteria to guide research, discovery, and development of new antibiotics. [Internet] 2017 Feb 27 [cited 2017 Aug 1]. Available from: http://www. who.int/medicines/publications/global-priority-listantibiotic-resistant-bacteria/en/

15. Kader AA, Kumar AK. Prevalence of extended spectrum beta-lactamase among multidrug resistant Gramnegative isolates from a general hospital in Saudi Arabia. Saudi Med J. 2004; 25: 570-74.

16. Khanfar HS, Bindayna KM, Senok AC et al. Extended spectrum beta-lactamases (ESBL) in Escherichia coli and Klebsiella pneumoniae: Trends in the hospital and community settings. J Infect Dev Ctries. 2009; 3(4): 295-99.

17. El-Khizzi NA, Bakheshwain SM. Prevalence of extendedspectrum beta-lactamases among Enterobacteriaceae isolated from blood culture in a tertiary care hospital. Saudi Med J. 2006; 27: 37-40.

18. Kader AA, Angamuthu K. Extended-spectrum betalactamases in urinary isolates of Escherichia coli, Klebsiella pneumoniae and other Gram-negative bacteria in a hospital in Eastern Province, Saudi Arabia. Saudi Med J. 2005; 26: 956-59.

19. Panhotra BR, Saxena AK, Al-Ghamdi AM. Extendedspectrum beta-lactamase-producing Klebsiella pneumoniae hospital acquired bacteremia. Risk factors and clinical outcome. Saudi Med J. 2004; 25: 1871-76.

20. Babay HA. Detection of extended-spectrum $\beta$-lactamases in members of the family Enterobacteriaceae at a teaching hospital, Riyadh, Kingdom of Saudi Arabia. Saudi Med J. 2002; 23: 186-90.

21. Yezli S, Shibl AM, Memish ZA. The molecular basis of $\beta$-lactamase production in Gram-negative bacteria from Saudi Arabia. J Med Microbiol. 2015; 64: 127-36.

22. Hassan MI, Alkharsah KR, Alzahrani AJ et al. Detection of extended spectrum beta-lactamases-producing isolates and effect of AmpC overlapping. J Infect Dev Ctries. 2013; 7(8): 618-29.

23. Alsultan AA, Aboulmagd E, Amin TT. ESBL-producing E. coli and K. pneumoniae in Al-Ahsa, Saudi Arabia: antibiotic susceptibility and prevalence of blaSHV and blaTEM. J Infect Dev Ctries. 2013; 7(12): 1016-19.

Date of Submission: 2017-09-18 Date of Acceptance: 2018-03-21 